\title{
Currículo de Autores
}

\section{Maigualida Bejas}

Doctora en Ciencias Políticas, con maestría en Geografía, mención Docencia. Licenciada en Educación, mención Ciencias Sociales. Con amplia experiencia en educación universitaria, investigación y gerencia de procesos académicos. Diversas publicaciones y diplomados en metodología de la investigación, numerosas asesorías y tutorías en las líneas de investigación: Educación, gerencia educativa, comunidades, ciudadanía y geografía.

\section{Sergio Linares Blanco}

Profesor en Artes. Mención Artes Musicales de la UPEL-IPC, Venezuel. Magister en Educación. Mención Estrategias de Aprendizaje, UPEL- IPM. Doctorando en Educación. UPEL- IPC. Director del Orfeón Universitario Juan Pablo Sojo. Director coral, compositor, arreglista e instrumentista profesional.

\section{Yasmin Pineda Ariza}

Docente de preescolar. Magíster en Educación, mención Planificación Educativa por la Universidad San Buenaventura, Colombia. Miembro del Proceso de Cualificación del Trabajo con familias orientadas al Fortalecimiento de Prácticas de Cuidado y Crianza y la Promoción del Desarrollo Infantil 2012 del Ministerio de Educación Nacional. Ha cursado diversos diplomados: Fundamento Político, Técnicos y de Gestión para la Atención Integral de la Primera Infancia por la Universidad del Magdalena; Derechos humanos para una educación inclusiva por la Facultad de Humanidades, Programas de Derecho y el Centro de Derechos Humanos del Caribe de la Universidad del Magdalena. 


\section{Currículo de Autores}

\section{Julio Salas González}

Doctorando en Educación. Magister en Educación, mención Estrategias de Aprendizaje. Profesor en Educación Musical. Experto en Procesos E-learning. Profesor agregado de la Universidad Pedagógica Experimental Libertador, Instituto Pedagógico de Miranda "José Manuel Siso Martínez". Jefe del Departamento de Expresión y Desarrollo Humano. Profesor del Área de Cultura en la Universidad Metropolitana.

\section{Ahiryn Andreina Yépez}

Profesora en Educación Musical y Magíster en Educación. Mención Estrategias de Aprendizaje, egresada de la UPELVenezuela. Diplomado Internacional de Música y Movimiento, Estudios musicales realizados en la escuela de Música "Prudencio Essá". Profesora del Pedagógico de Miranda en la Especialidad Educación Musical. 